\title{
Parques urbanos de Barcelona: relação entre usos principais e combinados, a diversidade nas formas de apropriação e a segurança
}

\author{
Simone Rechia* \\ Javier Olivera Betrán**
}

\begin{abstract}
Resumo: A intenção foi analisar o modelo de parques, praças e ruas de Barcelona com ênfase na relação entre diferentes formas de apropriação e a segurança desses espaços com base no conceito de usos principais e combinados de Jacobs (2000). Os procedimentos metodológicos foram: aplicação de protocolo desenvolvido no GEPLEC/UFPR, imagens fotográficas, filmagens e entrevistas semi-estruturadas com gestores e usuários. Concluiu-se que, em Barcelona, alguns espaços públicos contemplam tais formas de uso correlacionado, que dependem de uma série de fatores. Dentre esses, o planejamento urbano, que deve conectar espaços para garantir diversidade de experiências, a segurança, e, portanto, a "vida pública" nas grandes cidades.
\end{abstract}

Palavras-chave: Espaço público. Atividades de lazer. Segurança. Planejamento.

\section{INTRODUÇÃo}

A cidade, céu e inferno? Para Borja (2006, p. 2) "o céu é quando a cidade constrói lugares atraentes onde viver; o inferno é quando domina a arquitetura "urbanicida".

Jordí Borja (2006), geógrafo e urbanista, em seu texto intitulado "Urbanismo e Cidadania," reflete sobre o misto de céu e inferno hoje encontrado em Barcelona e também em diferentes cidades do mundo. Percebe-se que, muitas vezes e de forma simultânea, estão presentes nas cidades a distinção, a segregação e a proteção.

Vive-se, assim, uma época curiosa nos grandes centros

\footnotetext{
*Professora Curso de Educação Física da Universidade Federal do Paraná e do Programa de pós-graduação em Educação Física UFPR. Curitiba, PR, Brasil. E-mail: simonerechia@hotmail.com

**'Institut Nacional d'Educació Física de Catalunya. Catalunya, ES.
} 
urbanos, pois, ao mesmo tempo, frequentemente, exalta- se a cidade e se critica a violência urbana, o que Jordí Borja chama de arquitetura "urbanicida". Para ele, esse fenômeno,

É a expressão de um dos processos urbanos que negam a cidade; um urbanismo do medo, do medo à cidade; uma nova versão da rejeição que quase sempre manteve o pensamento conservador com respeito à cidade; um urbanismo de mercado que, em lugar de se enfrentar com seus efeitos desequilibradores, se adapta a suas dinâmicas, vende a cidade e deixa que se estenda uma urbanização difusa que multiplica as desigualdades sociais; um urbanismo que se expressa em arquiteturas banais, em blocos isolados e que, quando pretende ser monumental, costuma se converter numa afirmação do poder político ou econômico (BORJA, 2006, p. 2).

Esse processo gera categorias analíticas de extrema relevância para o campo sociológico, possibilitando, entre outras inúmeras indagações, questionar: Vive-se em cidades movidas pelo espetáculo ou pelo medo? As cidades produzem violência ou mercadoria a ser vendida e comprada? As experiências citadinas geram sentimentos de estranheza, insegurança ou identidade e segurança? Exercitam-se, cotidianamente, nos centros urbanos, o civismo ou o incivismo? A cidade de hoje assemelha-se à ideia de céu ou de inferno?

Para o referido autor, ao se afirmar que o planejamento urbano não é responsável pelas formas de uso e de apropriação dos espaços públicos das cidades, antes de culpar os cidadãos e de considerálos pessoas mal educadas para viver em sociedade, devem-se discutir algumas questões ligadas à urbanidade tradicional. Para começar, Borja (2006, p. 4) fala do "incivismo" do urbanismo real, pois, para ele, "com freqüência as políticas públicas são responsáveis ou cúmplices". Na sua visão, as formas de urbanismo atual muitas vezes se voltam para um urbanismo de produtos, que nega uma visão de cidade, como civitas ou polis, representada pela ágora, como expressão de civismo, tratando-a como oportunidade de negócio. Borja 
(2006) ressalta que, quando o promotor desse urbanismo de produtos é o setor público, o negócio pode consistir em realizar uma atuação socialmente necessária, entretanto, com o mínimo custo.

Dessa forma, o urbanismo de produtos configura-se resposta a duas dinâmicas próprias da economia urbana de mercado: a) transformação de grandes áreas centrais em espaços de consumo e de lazer submetidos a um uso especializado e depredador; b) dispersão para áreas periféricas de comunidades mais carentes, criando conjuntos habitacionais em territórios afastados com dificuldades de acesso ou desvalorizados economicamente.

Tais dinâmicas, ao gerarem distanciamentos entre pessoas de camadas sociais distintas, podem multiplicar os efeitos negativos da segregação social, permitindo inferir-se que a redução, a segregação ou a elitização dos espaços públicos é uma realidade do urbanismo atual. Esse fato conduz, muitas vezes, a uma vontade de proteger-se e de distinguir-se, vivendo em espaços privados em função da insegurança para apropriar-se de espaços abertos como ruas, parques e praças, podendo inibir, dessa forma, a experiência e o uso de espaços coletivos.

Observa-se que o modelo de bairros fechados, usuais nos Estados Unidos, começa a ser copiado em outros países, gerando-se a questão: Em ambientes fechados e distantes da vida pública, os cidadãos estão mais protegidos ou mais desprotegidos?

Nesse sentido, busca-se refletir sobre as problemáticas relacionadas à vida pública urbana. O objetivo do estudo aqui apresentado foi realizar uma análise de ruas, parques e praças de Barcelona, a partir do conceito de usos principais e combinados de Jacobs ${ }^{1}$, com ênfase na co-relação entre a diversidade nas formas de apropriação e a segurança.

\footnotetext{
${ }^{1}$ Segundo Jacobs (2000, p. 157) usos principais e combinados, referem-se a combinação de diferentes dinâmicas urbanas, as quais incluem diversidade de usos gerados a partir do comercio, atrativos culturais e moradia, atendendo de preferência mais de duas funções, garantindo um número grande de pessoas na rua em horários diferentes.
} 


\section{USOS PRINCIPAS E COMBINADOS DE RUAS, PRAÇAS, PARQUES, CENTROS COMERCIAS E RESIDENCIAIS}

Os espaços de lazer das cidades são, certamente, uma das preocupações mais presentes nas políticas públicas. São considerados lugares de socialização citadina por excelência, de potencialização de identidades culturais, de possibilidades de estabelecer relações multiculturais e integração social, aspectos que fazem parte de uma comunidade de convivência. Entretanto, segundo Jacobs (2000), são locais efêmeros, cujo desempenho nada tem de simples, uma vez que costumam apresentar extremos de popularidade e de impopularidade.

Ao analisar os parques das cidades dos Estados Unidos, a autora verificou que vários espaços foram construídos ao mesmo tempo, com desenhos idênticos e com os mesmos objetivos, porém, pela forma como foram usados, foram se tornando populares ou impopulares, seguros ou inseguros. Para a autora, um dos fatores que contribuem para a popularidade e, consequentemente, para a segurança, concentra-se na possibilidade de combinação de usos. Tal possibilidade ficará facilitada se houver casas, edifícios residenciais, edifícios empresariais, comércio, escolas e espaços culturais, no entorno dos espaços abertos de lazer. Essa afirmação está sustentada no fato de que a variedade de pessoas, que entram nesses locais e deles saem em horários diferentes, contribui tanto para a diversidade de usos e usuários dos parques, praças e ruas quanto para a sua segurança, pois geram constante movimentação, constituindo-se em espaços singulares dos bairros e trunfo econômico para a vizinhança.

Alguns espaços de Barcelona estão esvaziados e também sofrem a impopularidade. Segundo entrevistas realizadas com alguns usuários, tal desconforto está no fato de terem sido construídos em locais distantes, somente para a realização de eventos em períodos determinados do ano, causando certo sentimento de não pertencimento aos residentes do entorno. Aimagem abaixo revela tal fato, pois esse espaço intitulado Parc de Eventos Maresme Fórum, é interessante em termos de infraestrutura, no entanto parece ser "ilhado" não observando-se elos de identidade entre comercio, equipamentos e tempo/espaço de Lazer, permanecendo esvaziado na maior parte do tempo. 


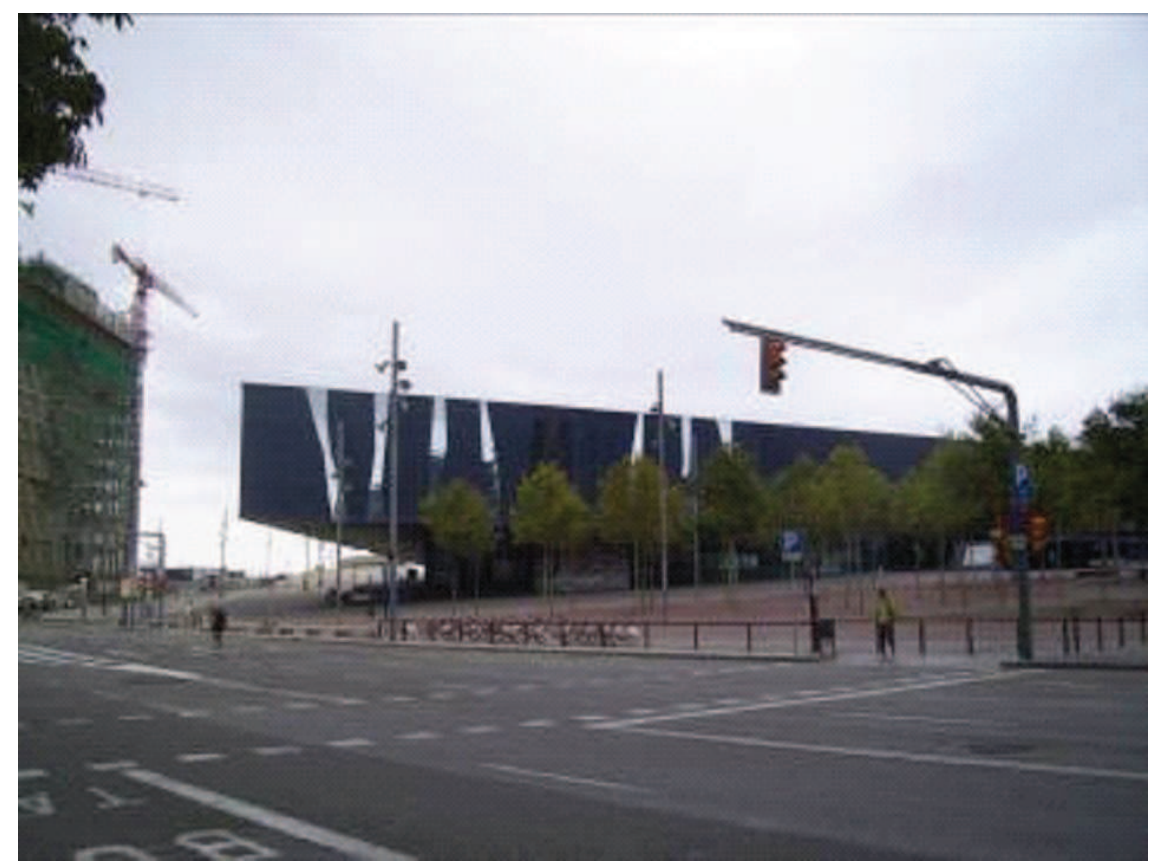

Figura 1 - Parc de Eventos Maresme Fórum

Logo, é importante considerar essa correlação entre usos principais e combinados dos espaços das cidades, quando se planeja um espaço de lazer. Nesse caso, as calçadas do entorno funcionam como excelente atrativo de pessoas, contanto que ofereçam acessibilidade a quem transita. Consequentemente, o uso das calçadas por elevado número de pessoas auxilia na segurança de todos os outros lugares. Segundo a Jacobs (2000, p.103) os parques, praças, espaços culturais e mesmo as calçadas "sofrem do mesmo problema das ruas sem olhos e seus riscos espalham-se pela vizinhança, de modo que as ruas que os margeiam ganham fama de perigosas e evitadas". Pode-se entender, então, que quanto mais pessoas se apropriarem dos espaços públicos, mais esses espaços poderão oferecer segurança para os cidadãos.

A autora salienta outro fator importante, a arquitetura dos espaços, a qual pode gerar a diversidade de usos ou seu "reducionismo", a vontade de usufruir dos espaços ou o medo de se aproximar, a apropriação dos lugares ou o esvaziamento. Isto quer dizer que, quanto mais variados forem os modelos arquitetônicos do lugar, mais atrativos eles se tornam. Os urbanistas devem estar atentos para esses fatores, se quiserem que as cidades tenham vida, diversidade e segurança, pois, segundo Jacobs (2000, p. 108), "a animação e a 
variedade atraem mais animação; a apatia e a monotonia repelem a vida".

Dessa maneira, conferir qualidade a todos os bairros, a todas as periferias, tornando-as visíveis e atraentes, socializando o uso dos centros e evitando tanto a especialização temática como a degradação, poderá significar construir uma cidade democrática em condições para o exercício da cidadania. Assim sendo, o espaço público polivalente, possibilita usos principais e combinados das populações e em temporalidades diferentes, como também permite a conexão desses ambientes com moradia e comércio. Tal conexão, poderá conferir sentido à vida citadina, marcar simbolicamente o território e potencializar elementos da identidade cultural e, evidentemente, proporcionar uma certa segurança.

\section{Caminhos metodológicos}

Para o referido estudo, realizou-se, metodologicamente, um mapeamento sobre alguns estudos ${ }^{2}$ referentes aos modelos de planejamento urbano de Barcelona, que abordam os espaços públicos e suas múltiplas interseções entre cultura, lazer e natureza e uma análise das ruas, parques e praças dessa cidade, com base nesses estudos e modelos.

Para o mapeamento desses estudos e desses modelos, contribuíram, sobretudo, levantamentos de fontes bibliográficas (livros, artigos e teses) realizados e disponíveis nas bibliotecas do Instituto Nacional de Educação Física da Catalunha (INEFC) da Universidade de Barcelona e em diversas bibliotecas públicas dessa cidade.

Para a descrição e a análise da cidade de Barcelona, além das fontes bibliográficas produzidas pelo INEFC e de teses relacionadas à temática central da pesquisa relatada, utilizaram-se, ainda, jornais e revistas, planos, mapas, legislações (documentos impressos), textos, vídeos e informações via internet (referências eletrônicas). Contribuíram, sobretudo, os levantamentos presenciais em

${ }^{2}$ Ver referencial bibliográfico

Wovimento, Porto Alegre, v. 16, n. 03, p. 181-202, julho/setembro de 2010. 
alguns espaços públicos da cidade registrados por meio de fotografias, observações sistematizadas, um diário de campo e entrevistas semi-estruturadas com usuários e gestores.

A seleção da cidade de Barcelona para essa investigação foi definida com base em estudos que a apontavam como um dos ambientes urbanos mais privilegiados em relação à diversidade de usuários e de formas de apropriação. Além disso, ela é amiudemente mencionada por especialistas em planejamento urbano, quando pesquisados acerca de algumas inovações nesse sentido.

Identificaram-se nessa cidade muitos focos de práticas simbólicas singulares e pertinentes à temática em investigação, constituindo-se, no motivo principal da pesquisa, sua relação com o meio urbano e os usos peculiares que oferece.

Entre os motivos secundários, estão: a grande quantidade de equipamentos de lazer, esporte e cultura disponíveis; sua extensão; infraestrutura (acessibilidade, iluminação, sistema de segurança pública, entre outros); vivências cotidianas da população local; localização geográfica privilegiada da cidade, ou seja, um eixo de ligação entre importantes cidades do mundo. Em resumo, trata-se de uma cidade singular, frequentada por diferentes grupos de pessoas que desfrutam dela de modos distintos.

\section{UM BREVE PASSEIO POR BARCELONA: LIMITAÇÕES E POTENCIALIDADES DOS ESPAÇOS PÚBLICOS}

As cidades atuais, e aqui especificamente Barcelona, formam um misto de céu e de inferno. A capital da Catalunha, uma das comunidades autônomas da Espanha, é cosmopolita por natureza. A população, segundo documentos oficiais (AJUNTAMENT DE BARCELONA, 2009, p. 9), está em torno de 3.000 .000 de habitantes, sendo que a Grande Barcelona chega a mais de 4.000.000 de habitantes. A cidade é bilíngue (castelhano e catalão), ocorrendo, nos últimos anos, forte intensificação no uso do catalão.

Embora um dos objetivos da pesquisa tenha sido analisar o 
planejamento urbano da cidade de Barcelona e seus espaços públicos de esporte e lazer, deve-se ressaltar a característica multíplice dessa cidade, tal qual um "mosaico de Gaudí"3 . Observa-se a coexistência de "várias Barcelonas" e, segundo Borja (2008, p.138), "cada uma é a materialização de diversos arranjos defensivos históricos e de vários planos urbanísticos, muitos elaborados a partir do século XVIII-XIX".

Os documentos oficiais do Ajuntament de Barcelona (1983) confirmam esse fato e relatam que vários planos fazem parte da história dessa cidade. Entre eles, destacam-se o de Idelfonso Cerda, que poderia ser caracterizado como um primeiro modelo de Barcelona, e as propostas de intervenção mais recentes, as quais deram origem a várias análises críticas, relatadas no livro de Horácio Capel (2005) intitulado El modelo Barcelona e no artigo de Jordí Borja (2004) intitulado Revolución y contrarrevolución en la ciudad global.

Barcelona é uma cidade interessante e contrastante, onde nativos e estrangeiros disputam espaços. Em que antigo se mescla com o moderno, apresentando edificações coladas umas às outras, com praças, parques, jardins e espaços vazios, tomados pela população nos momentos de lazer, mas que padece dos mesmos males de outras grandes metrópoles do mundo. Para Vásquez (2004, p. 71) "nem tudo é glamour nesse centro urbano". Há espaços bem estruturados, mas também grandes zonas marginalizadas, excluidas.

Nessa cidade, encontram-se espaços públicos convertidos em ambientes destinados a turistas, consumidores compulsivos da cidade, que modificam a rotina dos seus habitantes no uso de suas ruas, praças e parques. Notadamente, esses espaços ostentam uma arquitetura singular e emblemática de famosos artistas locais, muitas vezes demonstrando excessivo poder econômico aliado a um consumo dos lugares, como o Parc Güell com imensas filas de turistas

\footnotetext{
${ }^{3}$ Antonio Gaudí foi um arquitecto catalão, um dos símbolos da cidade de Barcelona, onde se educou e passou grande parte da vida. Aparece como um arquitecto de novas concepções plásticas ligado ao modernismo catalão. A influencia de Antoni Gaudí em Barcelona é muito forte pode-se encontrar as suas obras em vários bairros da cidade.Poderá visitar as suas obras como o Parque Guell, a casa Batlló, a casa Milà, ou a Sagrada Família, que todavia está em construção segundo os planos de Gaudí.
} 
em busca de uma foto das obras de Gaudí, espalhadas por todo o parque.

Considere-se também a Ramblas ${ }^{4}$, na Praça da Catalunha, principal rua do centro da cidade, fechada só para pedestres, mais um ícone desse espaço de consumo. Todos os dias, milhares de pessoas de todos os lugares do mundo transitam por esses lugares, observando-se umas às outras e admirando os prédios históricos, os monumentos, as obras de Gaudí e Mirós. Contemplam lojas, quadros, artesanato local, flores, animais, recebendo convites de restaurantes para experimentar comidas típicas e passeando por uma passarela com uma infinidade de paisagens, cheiros, cores e sabores.

Essas cenas se repetem em diferentes espaços da cidade: o Passeig de Gràcia, Mare Magnum, Vila Olímpica e seus entornos também são tomados pelos turistas, ouvindo-se todos os idiomas, vendo-se todas as etnias em distintos trajes, em uma demonstração de total diversidade cultural. Nos espaços destinados ao turismo, destacam-se o número de cafés e de restaurantes típicos e a exibição de encenações culturais das mais variadas formas, estátuas vivas, malabaristas. Nesses lugares, não há como passear ou desfrutar sem pagar, seja para sentar-se e descansar, seja para se distrair, a norma é consumir e arrecadar. Diante disso, em um primeiro momento, a cidade fascina pela sua magia, pela aventura de se virar uma esquina e encontrar pessoas e objetos diferentes a cada instante. Em um segundo momento, segundo Jordí Borja (2004), percebese que em ambientes dessa natureza - está presente a conexão do urbanismo de negócio, da ostentação do poder e do divinismo do artista, que se encontram na prática talvez inconsciente desse urbanicídio.

Nesse sentido, as pessoas de diversos lugares do mundo, que chegam para conhecer, aventurar-se, trabalhar ou estudar em Barcelona, deparam-se com um cotidiano pleno de oportunidades e dificuldades diferenciadas e "misturadas", tornando-as consumidoras da cidade. Muitas vezes, vivem em um bairro, divertem-se e

${ }^{4}$ Ramblas: ruas fechadas para trânsito de automóveis.

5Joan Miró i Ferrà foi um importante escultor e pintor surrealista catalão. 
trabalham em outro, têm relações sociais dispersas e mobilidade variável. Em muitos casos, esses sujeitos não se sentem pertencentes a um único lugar, mas a vários lugares.

Essa desterritorialização tende a gerar uma consciência crítica diluída e enfraquecida em função do sentimento de não pertencimento. Tal dinâmica distancia as pessoas cada vez mais da noção de família, de bairro. O lugar onde se trabalha ou se estuda já não está próximo a sua casa. Não há mais a permanência das relações de amizade vinculadas a um território específico. $\mathrm{O}$ esporte ou outras práticas sociais já não são vivenciados com os amigos da vizinhança. Não há mais motivos para o "bate-papo" na padaria, ou no bar da esquina. Os aspectos vinculados à civilidade, inclusive compromissos sociais, seja com a paróquia, com um partido político ou com vizinhos para discutir assuntos comuns que afetam a vida cotidiana, desaparecem.

Essa vida cotidiana nas grandes cidades, invadida por pessoas de diversas partes do mundo, transforma-se produzindo um aumento considerável da autonomia individual ou de grupo. Atualmente, em alguns casos, sentir-se autônomo significa poder ser "dono do próprio nariz", ser livre para estar cada vez mais só. Fato que, muitas vezes, se mede diante da possibilidade de viver em diferentes cidades, porém, conectados às pessoas por meio de equipamentos produzidos pela indústria do consumo como: telefone móvel, computador portátil, MPs, entre outros inúmeros artefatos derivados das novas tecnologias.

Nessa dinâmica, o núcleo social modifica-se, pois os espaços das cidades são vivenciados de maneiras difusas, gerando, com frequência, enfraquecimento de laços sociais e de vínculos identitários. Tais aspectos podem dificultar o exercício de valores cívicos, resultando em um "urbanicídio", mas também, segundo Jordí Borja (2006), podem "facilitar o surgimento de responsabilidades individuais". Para ele:

O cidadão metropolitano reage diante das incertezas presentes e futuras de sua vida frente à débil inserção num lugar e em uma 
comunidade. Também reage frente à falta de limites e de referenciais do território em que vive, movendo-se em direção à multiplicação de identidades sem que nenhuma seja dominante. Em consequência, aparecem comportamentos e demandas comunitaristas, que geram movimentos de revalorização da família, da religião e uma recuperação de identidades culturais perdidas, as quais produzem manifestações de apegos e defesa de territórios, cujo desejo é a reapropriação do seu lugar (BORJA, 2006, p.12).

Pode-se notar essa reação nas formas de apropriação de alguns parques, praças, jardins e ruas de Barcelona. Basta fazer um passeio por diferentes lugares e logo se depara com situações muito interessantes. Um exemplo típico está na Praça Gaudí, próximo à igreja da Sagrada Família. A apropriação dos espaços da praça se dá de diferentes formas, havendo nítida separação entre turistas e moradores nativos. Na entrada da praça, voltada para a igreja, encontram-se muitos turistas em quiosques, que vendem mapas, objetos típicos, cartões-postais. Dando alguns passos para o interior da praça, logo se encontram pessoas residentes no bairro, cuja língua falada é o catalão. Tais pessoas se apropriam dos espaços por meio do uso intenso e combinado de todos os "pedaços" da praça, das quadras de bocha pelos idosos às áreas de recreação infantil pelas crianças.

Igualmente, pode-se perceber que o cidadão estabelecido em Barcelona encontra os próprios espaços em outras praças, ramblas e parques não tão visados pelos turistas. O Passeig de San Joan, a Rambla de Poblenou, o Parc de La Barceloneta, a Plaza Virreina, a rua Asturies no bairro Grácia, a Plaza Lesseps, entre outros inúmeros lugares, são tomados totalmente pela população nativa. Nesses espaços, encontram-se crianças, adultos e idosos, que, mediante usos principais e combinados, vivenciam de maneira intensa e das mais variadas formas e momentos a vida pública na cidade.

Nas praças e parques públicos, destaca-se elevado número de bancos e áreas livres para conversar, descansar, jogar, brincar, praticar esporte, andar de bicicleta, entre outras. No Parc de La Barceloneta, percebe-se nítidamente um dos modelos de parques 
públicos de Barcelona. Esse parque é bem estruturado, com numerosos bancos em áreas estratégicas e mirante de vista para o mar, além de áreas infantis com brinquedos diversificados. Contempla, ainda, espaços cobertos, os quais possibilitam práticas variadas em dias de frio e de chuva. Outra característica interessante é a de oferecer muitas áreas livres estruturadas sem demarcações ou induções para determinadas práticas, amplamente acessíveis e com iluminação e excelente manutenção.

Nota-se, ainda, em muitos parques, a superação do entendimento de espaço público ou espaço verde como espaços segregados e especializados. Um exemplo dessa dinâmica é o Parc de La Ciutadella (ver fig. 2, 3, 4), referência tanto física como simbólica para a cidade. Esse espaço demarca limites e estabelece continuidades, é polivalente e também muito acessível. É um lugar de passagem próximo ao centro, com aspectos turísticos, mas também de repouso e de práticas vinculadas à cultura corporal e artística do lugar.

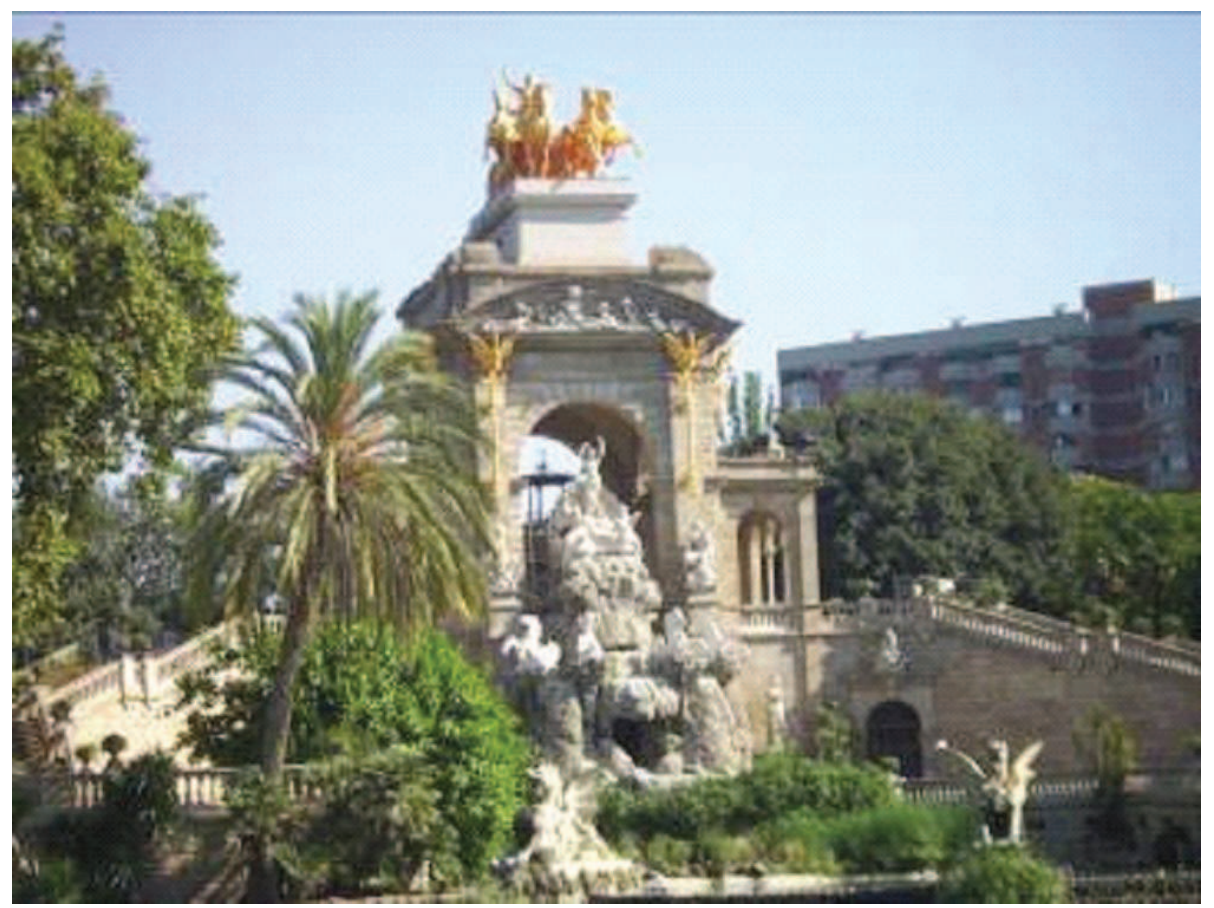

Figura 2 - E1 Parc de La Ciutadella 


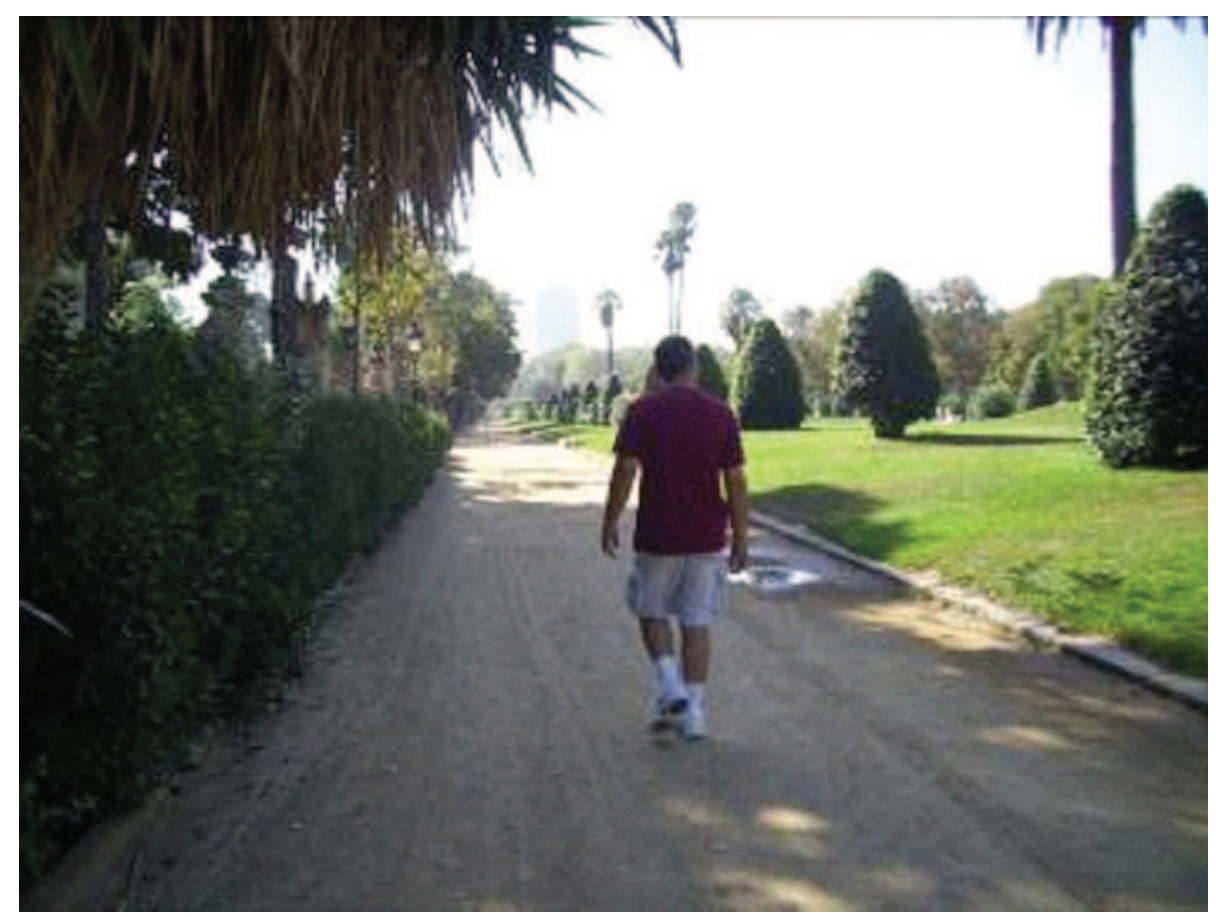

Figura 3 - El Parc de La Ciutadella - (espaços para práticas corporais)

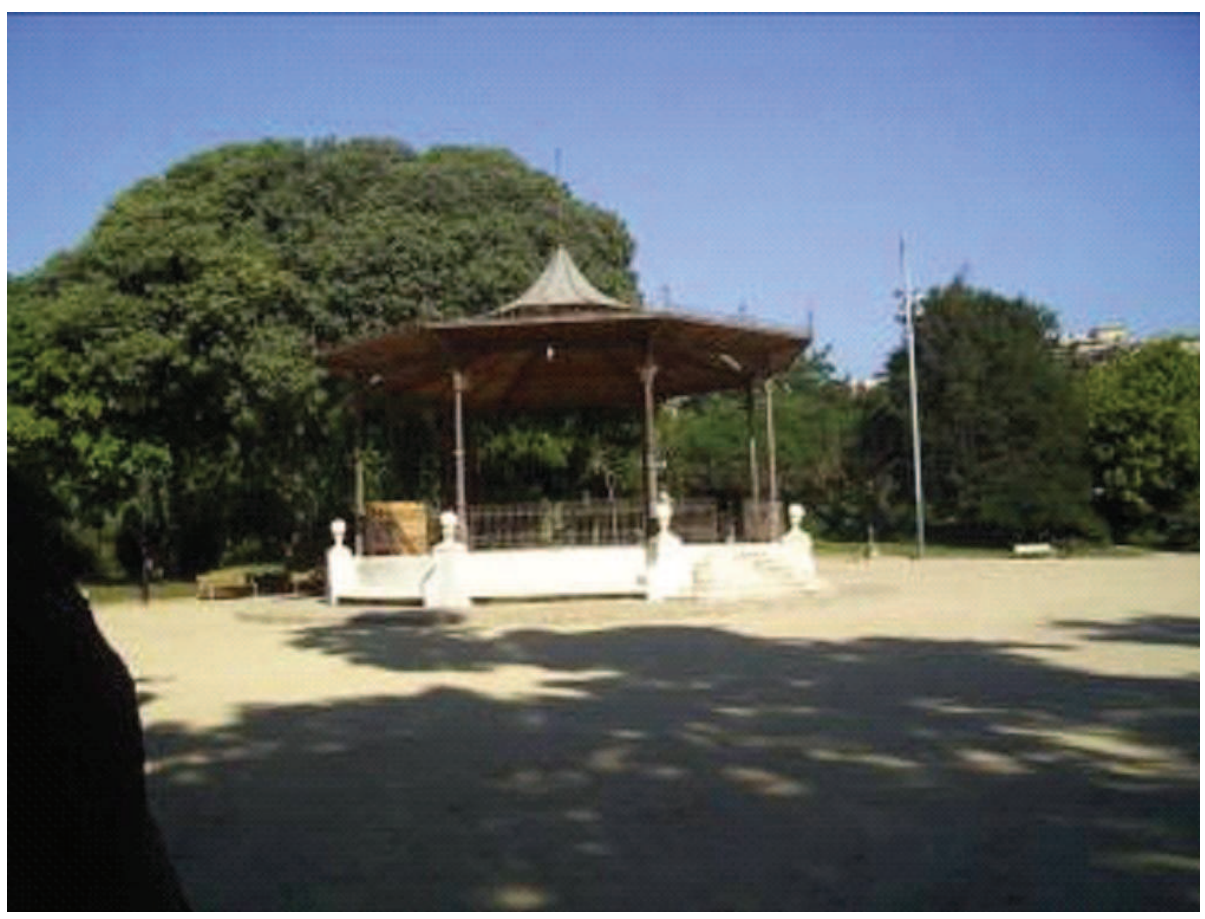

Figura 4 - El Parc de La Ciutadella (espaço onde se realizam várias práticas culturais)

Constata-se que em Barcelona a idéia de praça apenas entendida como lugar de circulação foi transformada em uma idéia de praça como lugar de encontro, de atividades lúdicas, culturais, es- 
portivas, ou seja, em espaços cívicos. A Praça Lesseps, situada na conexão entre os bairros Sant Gervasí e Grácia, é um bom exemplo dessa concepção (ver fig. 5, 6).

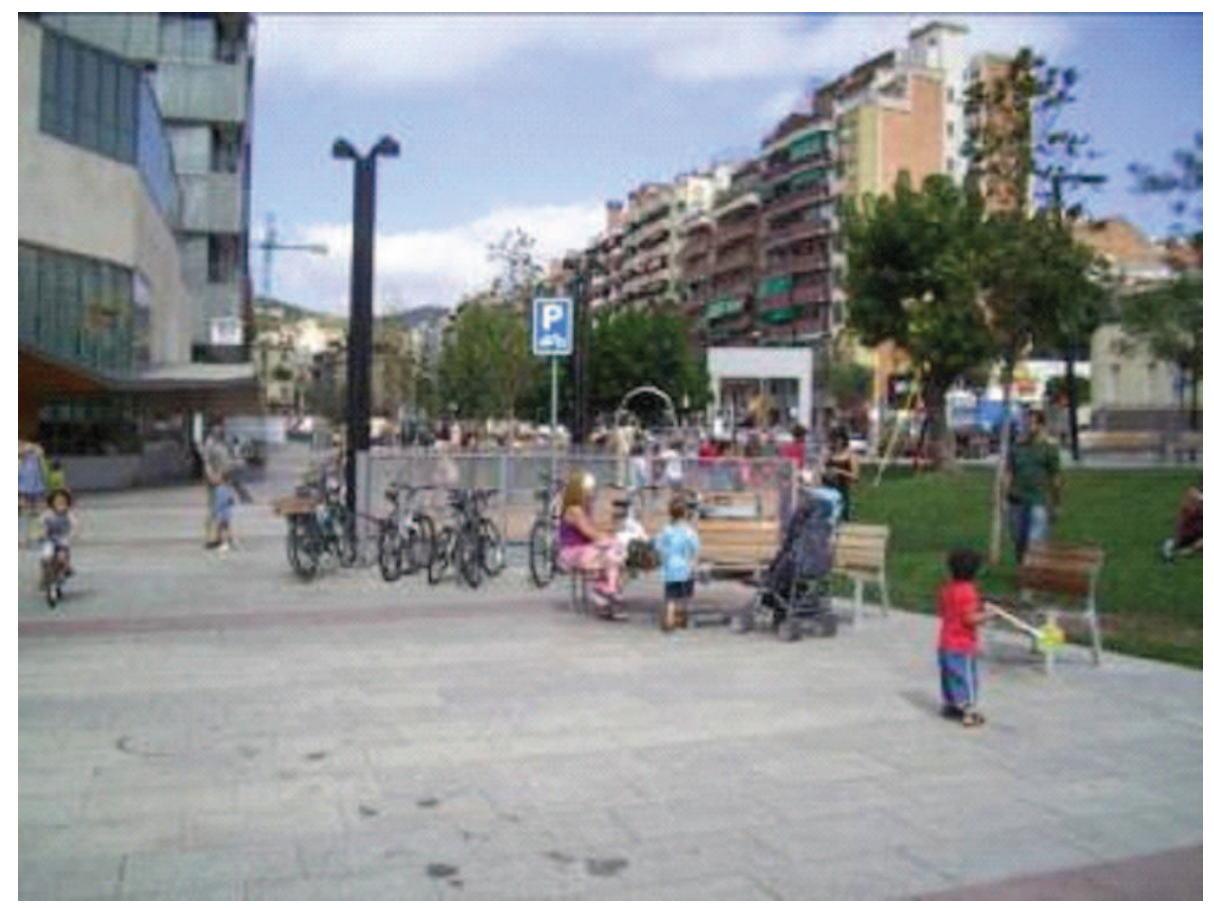

Figura 5 - Praça Lesseps (um dia de verão pela manhã)

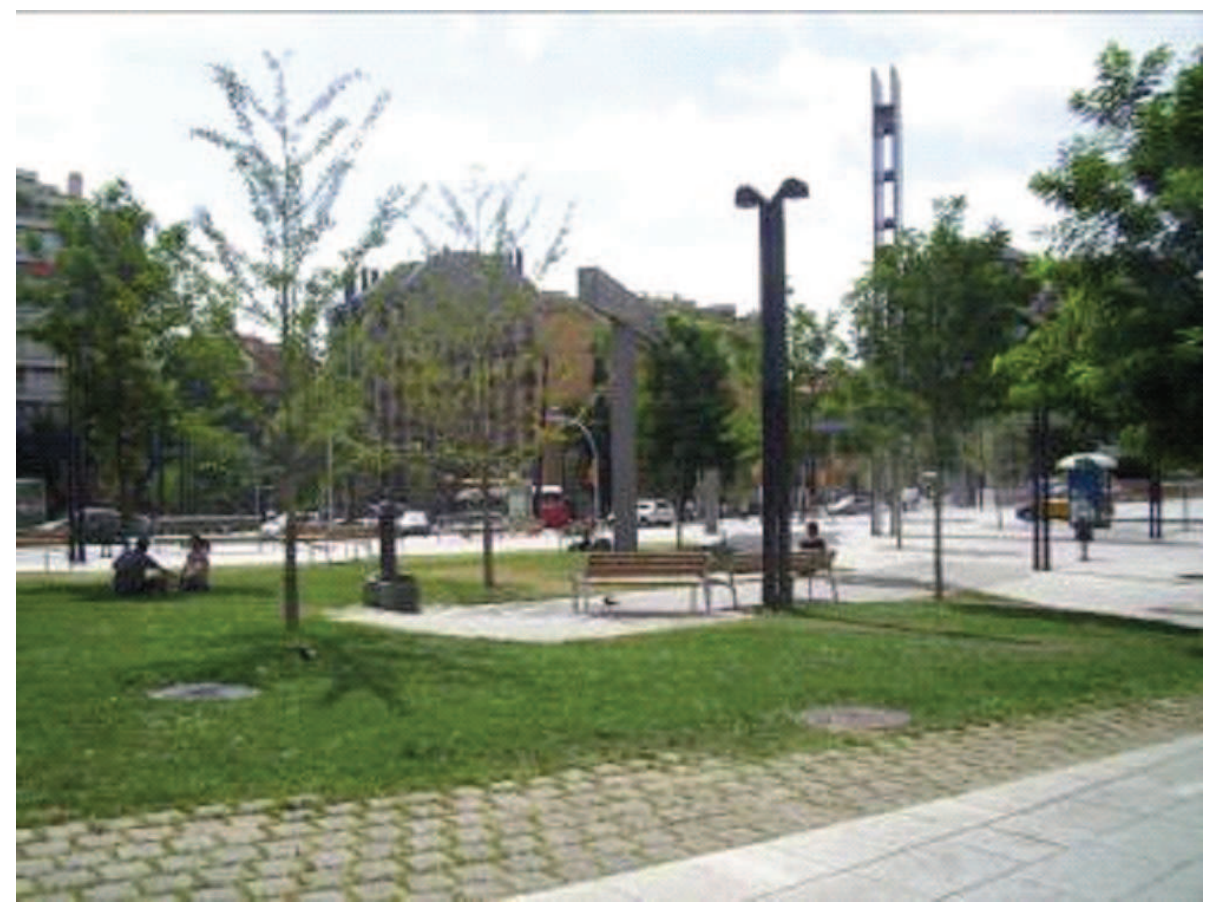

Figura 6 - Praça Lesseps (organização do mobiliário da praça, com vários pontos de encontro) 
Os dados dessa investigação apontam que algumas ruas, praças e parques de Barcelona reagem a esse "urbanicídio", pois são espaços coletivos por excelência. Essa questão está vinculada a importante entendimento do urbanismo moderno em (re)valorizar tais ambientes muitas vezes com mais ênfase cultural do que no próprio desenho urbano. Segundo Borja (2006), a boa fama de Barcelona, e em geral das cidades europeias, se deve, principalmente, "a seu urbanismo cidadão, à qualidade do espaço público e à vida urbana que permitem".

Outro ponto relevante na organização dos espaços das cidades, assinalado por Jordí Borja (2006, p.20), está "na relação com a circulação que vai se modificando pouco-a-pouco. Se, nos anos 60, reduziam-se as calçadas e suprimiam-se os bulevares ou ruas ajardinadas para facilitar a circulação motorizada, a partir dos 80, inicia-se uma tendência de signo contrário". Dessa forma, pensa-se mais na circulação das pessoas, valorizando-se os espaços para pedestres. Observa-se essa tendência em Barcelona, pois, as ruas são estruturadas e possibilitam a mobilidade urbana com percursos específicos para usufruir a vida pública de forma intensa (ver fig. 7 , 8).

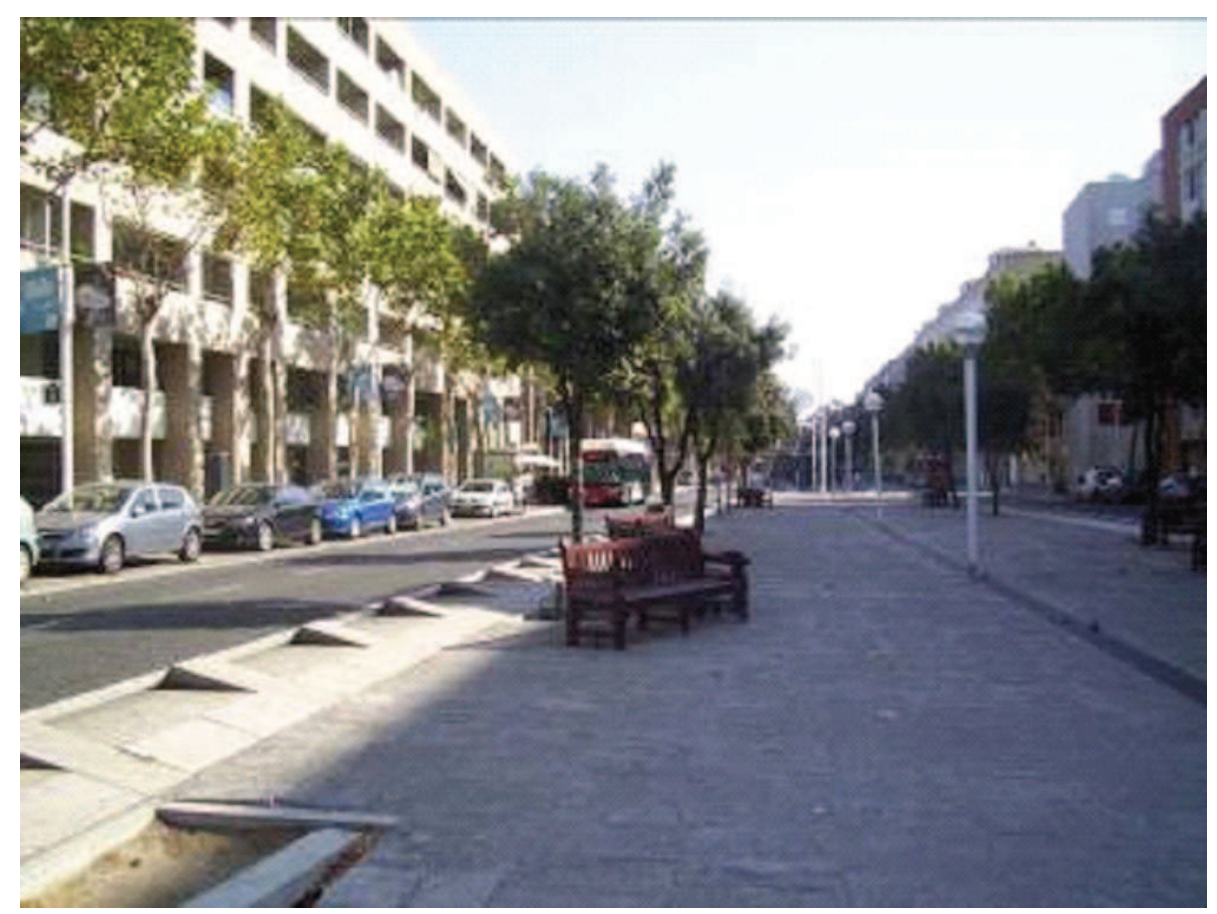

Figura 7 - Rambla Prat: rua fechada, larga, só para pedestres e ciclistas, com bancos, iluminação e áreas com brinquedos infantis. 


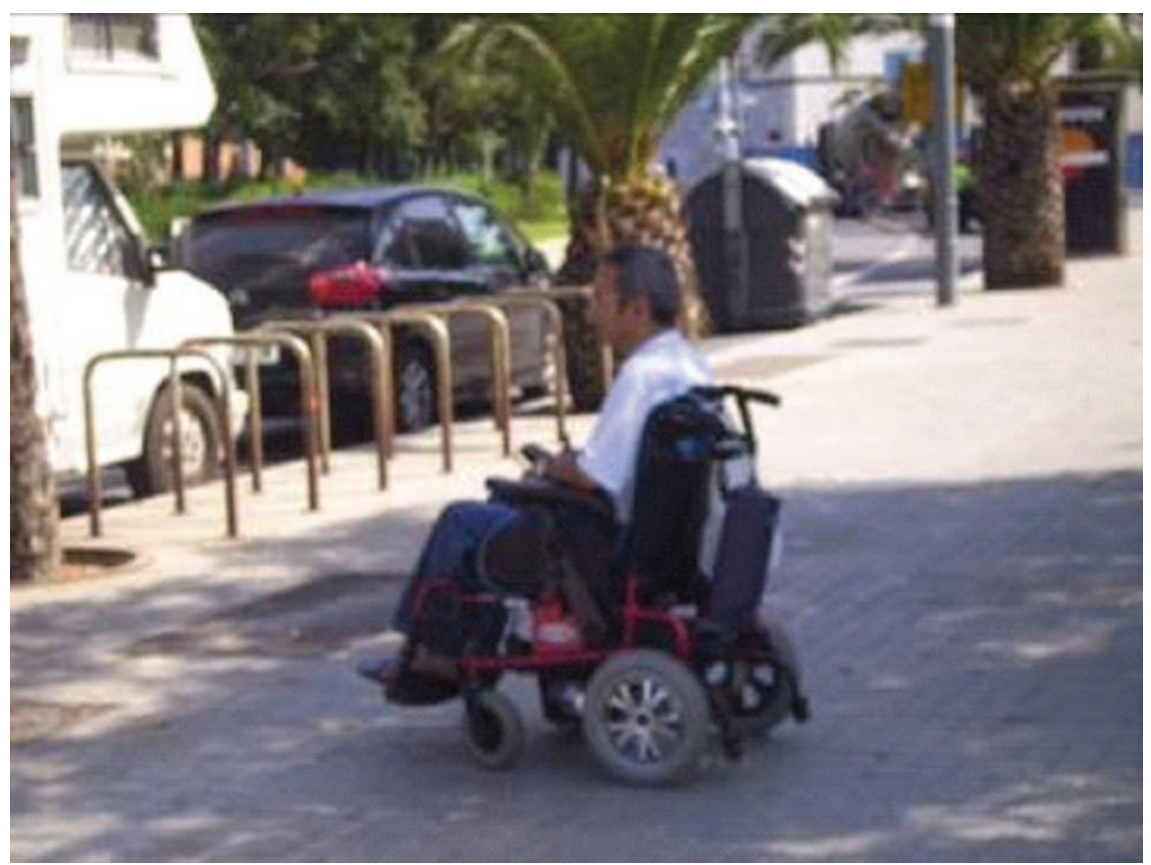

Figura 8 - Rua com acessibilidade, só para pedestres e ciclistas, situada no Bairro Villa Olímpica - Pg.Marítim Del Pot Olímpic

Para Borja (2006), em Barcelona e em outras cidades europeias, pretende-se que grande parte da mobilidade urbana diária se realize a pé. Para tanto, segundo ele, "o caminho mais perto entre dois pontos deve ser também o mais bonito", daí porque os trajetos de Barcelona oferecem praças, ruas só para pedestres, jardins e parques lineares (ver fig. 9).

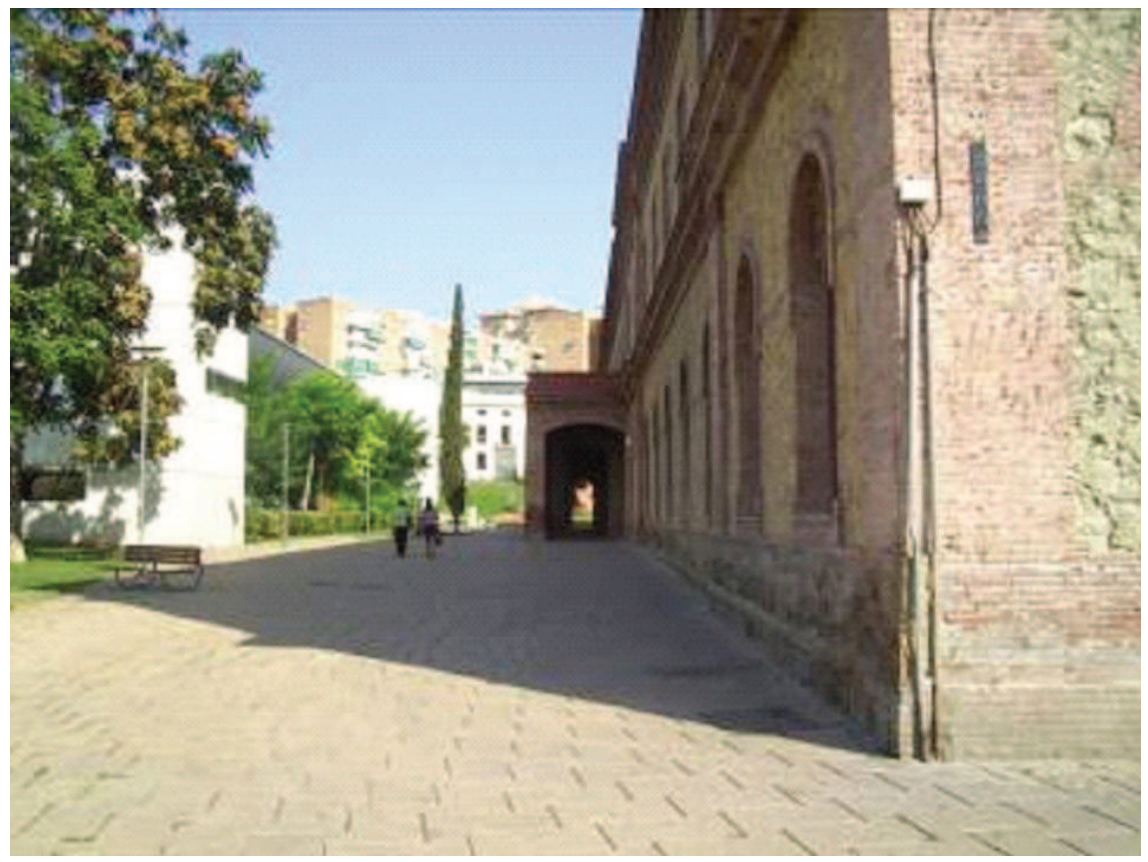

Figura 9 - Rua de conexão entre o Distrito Nou Barris e o Parc Central Nou Barris

Wovimento, Porto Alegre, v. 16, n. 03, p. 181-202, julho/setembro de 2010. 
Essa cidade proporciona diferentes vias de acesso conectadas entre si como: amplas calçadas, ruas fechadas para automóveis, autopistas, ciclovias (ver fig. 10). Sobressaem as ruas fechadas para trânsito de automóveis, intituladas ramblas, associadas a ciclovias, praças e parques lineares, que possibilitam tanto andar a pé como de bicicleta, descansar, contemplar, brincar, ou experienciar alguma prática da cultura local.

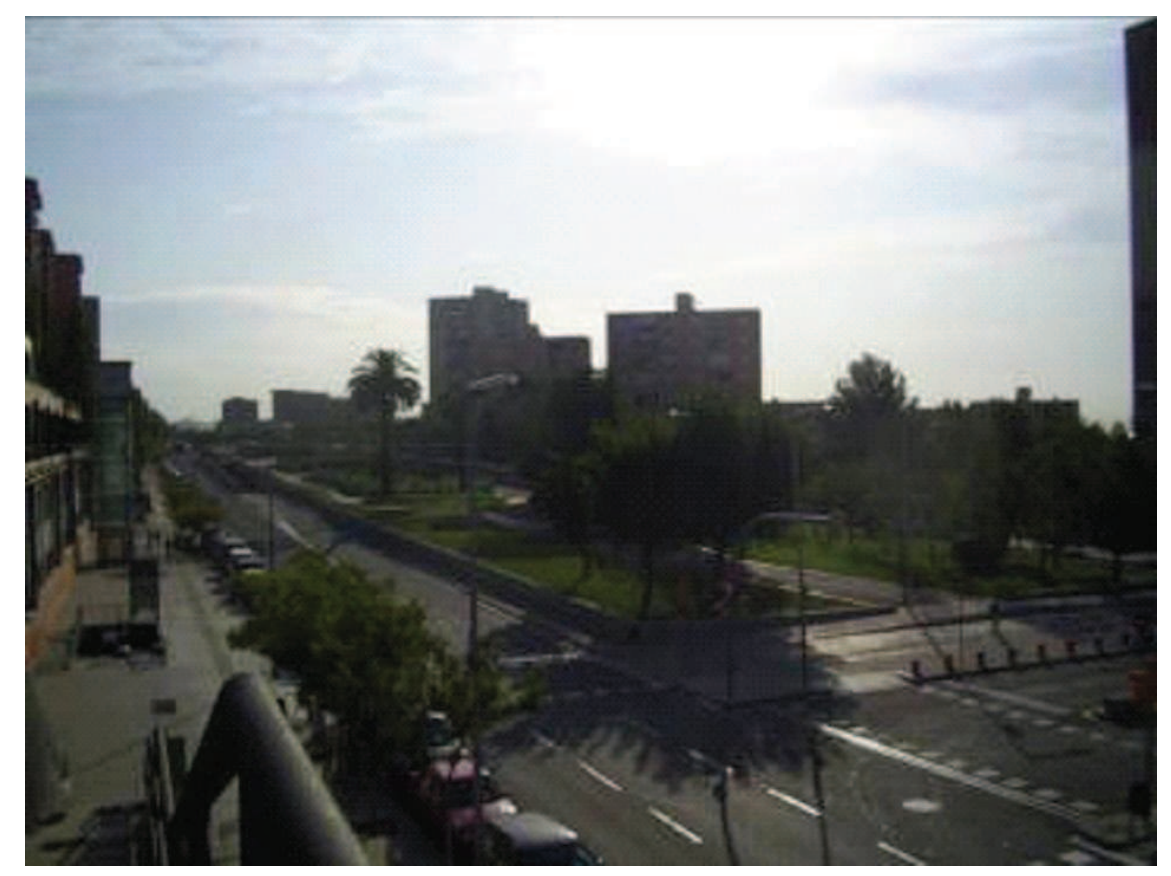

Figura 10 - Vista de cima da Ronda de Dalt: conexão entre autopistas, calçadas, ciclovias, parques lineares, praças

Outro ponto fundamental é que, em muitos casos, o acesso a parques e praças está muito próximo de pontos de metrô, comércio local, bibliotecas, teatros e outros espaços culturais. Em cada pedaço desses territórios, encontram-se monumentos, obras de arte ou exibições de artistas locais (ver fig. 11), conferindo, de certa forma, densidade cultural aos espaços. 


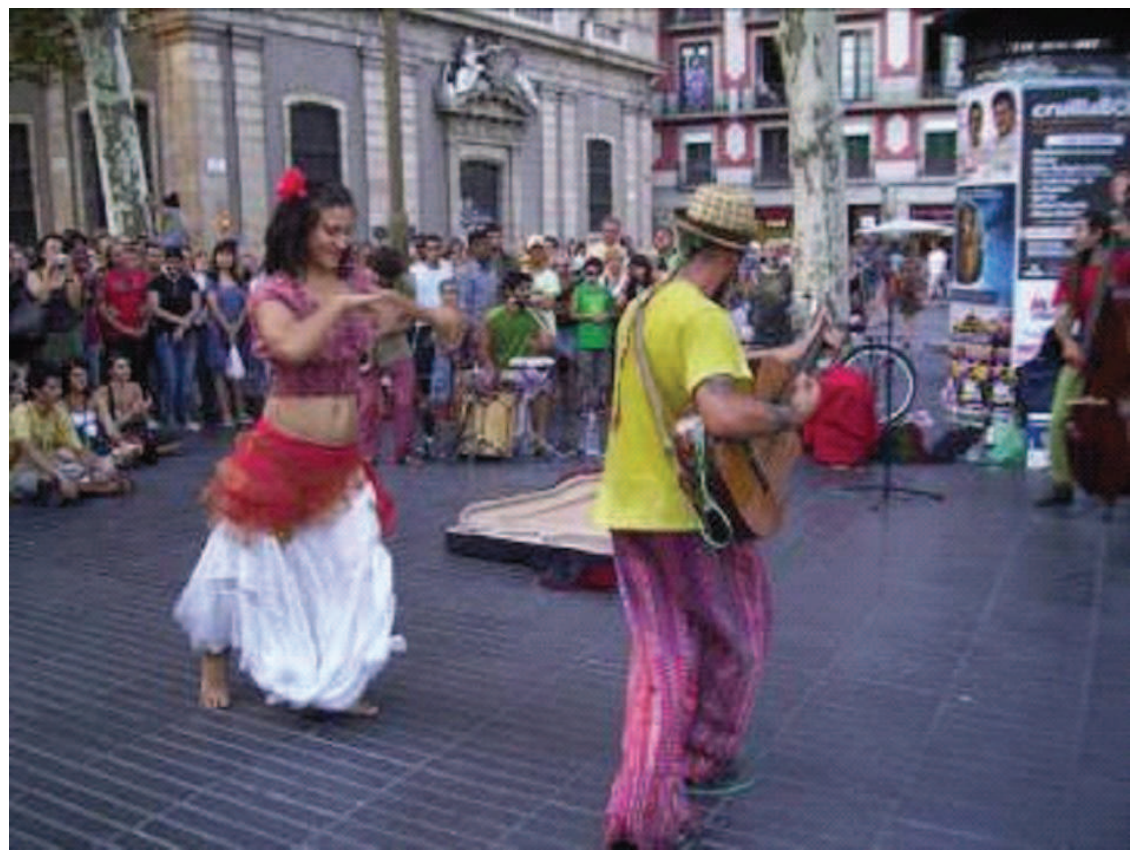

Figura 11 - Rambla próxima ao Bairro Gótico

Nesse sentido, Borja (2006) ressalta que o espaço público é o lugar da cultura e da festa, mas também da manifestação política (ou cívica), do protesto e da revolta, resultando que a qualidade formal do espaço público não é uma questão secundária.

Para Borja (2004, p.18), "a paisagem urbana é nossa casa grande, se não é bonita e funcional, cômoda e agradável, estimulará comportamentos pouco cívicos. A atenção aos materiais e ao mobiliário urbano, à limpeza e às contaminações (acústica, atmosférica, etc.), à publicidade excessiva e ao aspecto das fachadas, e, em definitivo, a tudo aquilo que configura a paisagem urbana é condição necessária do civismo."

Tais aspectos proporcionam elementos de identidade ou de diferenciação a cada bairro ou distrito da cidade. Por isso, pode significar contribuir com a cidadania manter e cuidar dos espaços como o Parc Central de Nou Barrius, situado no bairro Nou Barrius, em Barcelona, (ver fig. 12), ligando-se a várias ruas que facilitam a mobilidade diária, articulando o trabalho e o lazer com atenção especial ao aspecto da convivência, além de potencializar os espaços coletivos. 


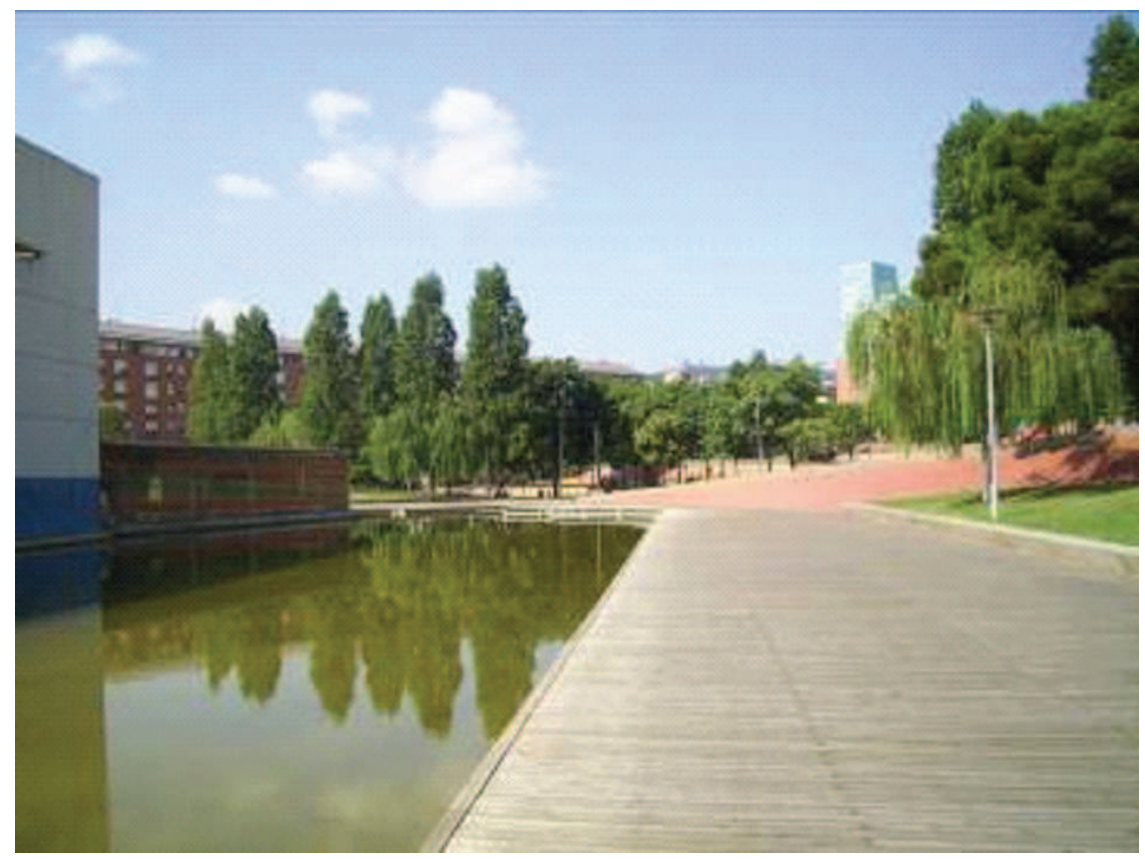

Figura 12 - Parc Central de Nou Barris

Jordí Borja (2006, p. 12) ressalta que "investir na qualidade do espaço público, de seu desenho, de seu enriquecimento e de sua manutenção nunca será um luxo, senão justiça democrática".

\section{CONSIDERAÇÕES FINAIS}

Concluiu-se que, em Barcelona, o uso dos espaços públicos de lazer é potencializado pela correlação entre usos principais e combinados de diversos espaços da cidade, os quais desempenham, muitas vezes, mais de duas funções e garantem alto número de pessoas nas ruas em horários diferentes. Dessa maneira, geram interessantes experiências pessoais, associadas à variedade de tipos de pessoas, interesses, atividades, empreendimentos públicos e/ou privados e também ao exercício da cidadania.

Os espaços investigados pela pesquisa relatada demonstram as características necessárias para gerar diversidade e segurança, ao possibilitarem o trânsito de pessoas diariamente, que se apropriam do espaço público de diferentes maneiras. As possibilidades geradas pelos espaços em referência constituem facilitadores para o 
encontro entre os moradores dos bairros, por meio do uso compartilhado dos equipamentos e das formas de organização e manutenção dos lugares.

Dessa maneira, evidenciou-se que a conexão de usos principais com usos combinados interfere nas formas de apropriação relacionadas com a segurança do lugar. Entretanto, essa ocorrência depende de uma série de fatores, principalmente do planejamento urbano, que ao buscar o desenvolvimento e a potencialização dos espaços, poderá de algum modo garantir a diversidade de experiências, por conseguinte, a "vida pública" nas grandes cidades.

Borja (2004 apud CAMPOS, 2004, p. 10) salienta que, para se alcançar tal dimensão da vida pública, "os governos urbanos haverão de assumir pautas socio-culturais múltiplas, onde a segurança não apareça como conseqüência, mas sim, como um direito a um projeto de vida, como os demais direitos".

Barcelona's urban parks: the relationship
between different forms of appropriation and
safety from major and co-related uses
Abstract: The intention this paper was to analyze the
model of Barcelona's parks, plazas and streets,
emphasising the relationship among different forms of
appropriation and safety of these spaces, based on
the concepts of major and co-related uses from
JACOBS (2000). The methodological procedures were:
application of the protocol developed by GEPLEC/UFPR,
photographic images, films and semi-structured
interviews. In conclusion, we can infer that some
Barcelona's public spaces include such forms of co-
related use, which depend on a number of factors,
among them, urban planning, which should connect
spaces in order to ensure diversity of experiences,
safety, and therefore the "public life" in big cities.
Keywords: Public space. Leisure, activities. Safety.
Planning.

Lovimento, Porto Alegre, v. 16, n. 03, p. 181-202, julho/setembro de 2010. 


Parques urbanos de Barcelona: la relación en-
tre la diversidad en las formas de apropriedad
y de seguridad de los principales usos y com-
binados
Resúmen: La intención fue analizar el modelo de los
parques, plazas y calles de Barcelona con énfasis
en la relación entre las diferentes formas de
apropriedad y la seguridad de estos espacios basados
en los usos principales y combinados de JACOBS
(2000). Los procedimientos metodológicos fueron:
aplicación del protocolo desarrollado en el GEPLEC/
UFPR, imágenes fotográficas y rodaje. Se concluyóó
que en Barcelona algunos espacios públicos
contemplan tales formas de usos co-relacionados,
los cuales dependen de una serie de factores. Entre
estos, la planificación urbana, que también debe
conectar espacios para garantizar la diversidad de
experiencias, la seguridad, y, por lo tanto, la vida pú-
blica en las grandes ciudades.
Palabras -clave: Espacio público. Ocio. Seguridad.
Planificación

\section{REFERÊNCIAS}

AJUNTAMENT DE BARCELONA. Plans i Projectes per a Barcelona 1981-1982. BCN: Ajuntament de Barcelona, Área d' urbanisme. Barcelona, 1983.

Barcelona: espaço público. Barcelona, 1993.

Barcelona: Pressupost 2009, Llum verd al benestar dels ciutadans. Barcelona, 2009.

BORJA, Jordí. Urbanismo e cidadania. In: CIVISMO: las claves de la convivência. Barcelona, 2006. Los monográficos de B.mm, n.6.

Revolución y contrarrevolución en la ciudad global. Madrid: Alianza, 2004.

CAMPOS, Antoni Carlos. A cidade, espaço de convivência. Revista Bibliográfica de Geografía y Ciencias Sociales, Barcelona, v. 9, n. 546, 15 nov. 2004.

CAPEL, HORÁCIO. El modelo Barcelona: un examen crítico. Barcelona: Ediciones del Serbal, 2005. 
JACOBS, Jane. Morte e vida das grandes cidades. São Paulo: Martins Fontes, 2000.

VÁZQUEZ, Carlos Garcia. Ciudad hojaldre: visões urbanas del siglo XXI. BarceIona: Gustavo Gili, 2004.

Recebido em: 13.11.2009

Aprovado em: 22.05.2010

Wovimento, Porto Alegre, v. 16, n. 03, p. 181-202, julho/setembro de 2010. 